\section{Qualitative relationships are decisive}

\author{
ALAN L. GILCHRIST \\ Institute of Cognitive Studies \\ Rutgers-The State University, Newark, New Jersey \\ and

\section{ALAN JACOBSEN \\ Boeing Commercial Airplane Company \\ Seattle, Washington}

In Heinemann's (1989) welcome commentary, a deeply rooted dispute has become clearly joined. Heinemann comes to the defense of a widely shared view of lightnessbrightness perception, according to which (1) visual processing ultimately is based on absolute luminance values, (2) a contrast mechanism is introduced to account for relational findings, and (3) quantitative values are the important ones. We would support an alternative view in which visual processing is based solely on relative luminance values, a contrast mechanism is neither required nor helpful, and qualitative relationships are crucial.

1. Heinemann asserts that we are reviving Katz's (1911/1935) lightness-brightness distinction. We cannot accept the flattery, however, since both the data base supporting the distinction and its acceptance by the vision community have continued to grow quite independently of our work. One can cite Evans (1974), Beck (1972), Lie (1969), Heggelund (1974), Wyszecki and Stiles (1967), and Arend and Goldstein (1987) as a partial list of those who employ the distinction.

It should be further noted that the lightness-brightness distinction is not the same as Katz's distinction between the surface-color mode and the aperture-color mode, as Heinemann suggests. Only brightness is an attribute of film colors, while both lightness and brightness are attributes of surface colors.

We offered the claim that observers tend to match ratios when the matching field is a decrement and tend to match luminances when the matching field is an increment. (For clarity we will use Heinemann's, 1961, terms "target field" and "matching field" throughout.) Heinemann challenges that claim by reference to both our data and his.

Citing our data (Jacobsen \& Gilchrist, 1988a), he points out that we obtained ratio matches even though three of the five targets in our target display were increments. Our point about increments and decrements, however, refers to the matching display, not the target display. We should have made this distinction more clear in our publication, although it was implicit in our design, and Heinemann faithfully conveyed the distinction in his commentary.

Correspondence may be addressed to Alan L. Gilchrist, Institute for Cognitive Studies, Rutgers University, Newark, NJ 07102.
Heinemann offers his own 1961 data as a demonstration that "the steepness of the matching curves seems to be a continuous function of the luminance of the area surrounding the [matching field]." In fact, however, his Figure 1 does not show the continuous and fan-like set of straight lines suggested by his quantitative approach. Closer inspection reveals that each curve, especially the middle ones, begins with a horizontal component on the left, followed by a slope of approximately +1 . The elbow occurs where the matching field (again, not the target field) changes from a decrement to an increment (note that this is where the ordinate value surpasses the parameter value, not where it surpasses the abscissa value). His slopes in the incremental region are very similar to our brightness data, as can be seen in our Figure 1 .

Heinemann asserts that "the general statement that the ratio principle does not hold for increments is clearly wrong." This is correct if the term "general statement" is taken to mean "ironclad rule" rather than "strong tendency." We noted, for example, that "when the paradigm is changed ... as in Whittle and Challands (1969), strict ratio results are obtained for increments as well'" (Jacobsen \& Gilchrist, 1988b, p. 8). The Fry and Alpern (1953) study cited by Heinemann is similar in design to the Whitthe and Challands study. Heinemann's curves A, B, and $\mathrm{C}$ (from his 1955 study) appear to constitute a further exception to the rule.

A more complete picture emerges from a carefully controlled study by Arend and Goldstein (1987), who were able to obtain ratio matching and luminance matching using both increments and decrements by relying on lightness or brightness instructions to subjects.

Perhaps our position can be summarized most clearly as follows. There are three interrelated statements that tend to be true: (1) Incremental matching displays evoke luminance matches, while decremental matching displays evoke ratio matches; (2) incremental matching displays evoke brightness matches, while decremental matching displays evoke lightness matches; and (3) brightness instructions evoke luminance matches, while lightness instructions evoke ratio matches. As can be seen clearly in the Arend and Goldstein data, the cleanest luminance matches are obtained when brightness instructions are combined with an incremental matching display and the cleanest ratio matches are obtained when lightness instructions are combined with a decremental matching display.

2. We claimed that the Jameson and Hurvich (1961) finding that dark grays appear blacker as the illumination increases is "essentially unreplicable." Heinemann finds the justification for this claim unclear since "the results of Jacobsen and Gilchrist (1988a) are based on just 3 subjects and no statistical analysis was presented."

First, our results are based on 9 subjects, not 3 . We presented a graph of only one condition, but as can easily be seen from Table 1 (Jacobsen \& Gilchrist, 1988a, 

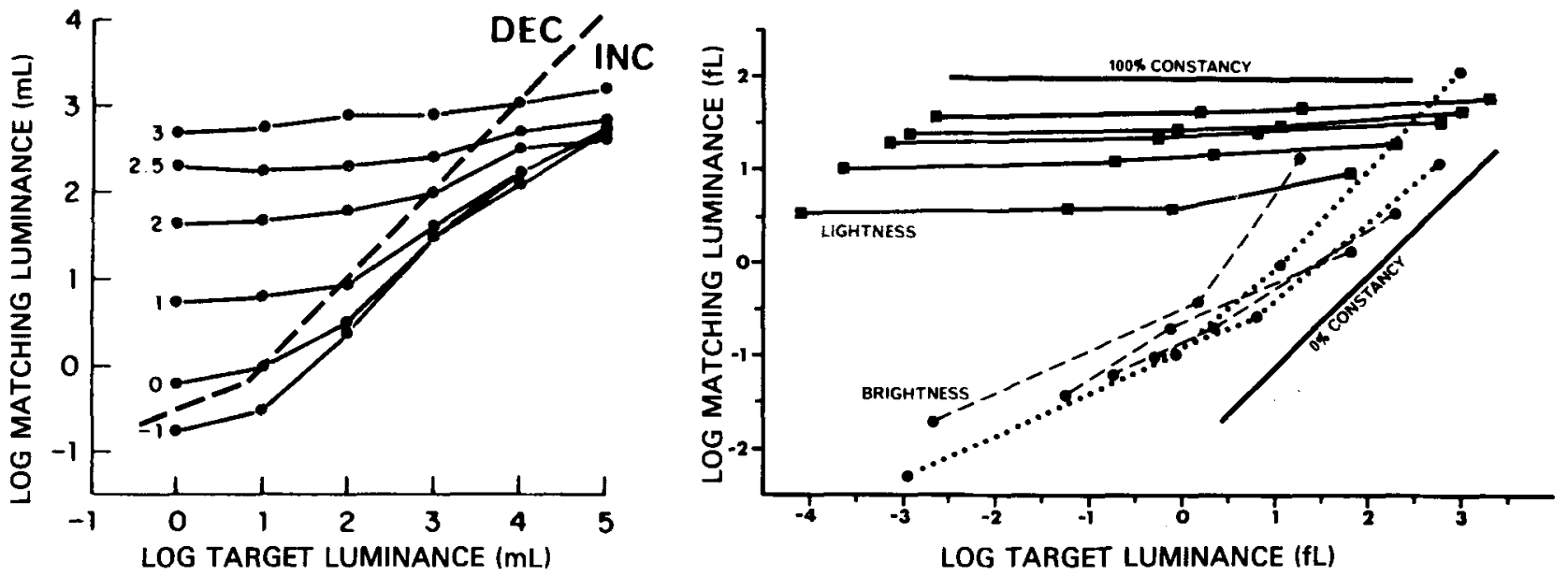

Figure 1. Heinemann's (1961) data (segregated for decremental and incremental matching fields) compared with data from Jacobsen and Gilchrist's (1988a) study.

p. 4), the 6 subjects in the two alternative conditions gave essentially the same results. We note, however, that there were only 3 subjects on which the original Jameson and Hurvich (1961) claim was based. Those 3 subjects were the authors and one of their graduate students.

Second, although perhaps we should have pointed this out, no trend analysis of our curves was warranted since we obtained nine separate curves (three types of match $x$ three viewing conditions) for the black target, and none of these showed a negative slope at all. Neither were there any negative slopes in the raw data for individual subjects.

We also cited three other exact replications of the Jameson and Hurvich study (Flock \& Noguchi, 1970; Haimson, 1974; Noguchi \& Masuda, 1971), all of which failed to find any negative functions. The studies that Heinemann claims agree with Jameson and Hurvich-Helson (1943) and Heinemann (1955) - were merely similar, not replications, and the results match those of Jameson and Hurvich only in the barest way.

Finally, even Heinemann's report from his own data that "increases in absolute luminance level can result in a darkening of the test field, to be followed at still higher luminances by a brightening of the test field" seems like weak support for the Jameson and Hurvich theory of diverging functions, according to which one would not expect such a brightening.

3 . Heinemann argues that there is no contradiction between Wallach (1948) and Hess and Pretori (1894) since their results are virtually identical "under the conditions common to the two experiments." This is only partly correct.

When Hess and Pretori's observers produced a series of ratios on the matching display (on the right) to match a constant target display (on the left), they produced a series of ratios that were the same as each other, but not the same as the target display. In this, their results were quite unlike those of Wallach. In fact, Hess and Pretori's observers often matched an increment on the left side to a decrement on the right side, a serious violation of the ratio principle that never occurred in Wallach's data. This happened in both curves 11 and 12 , mentioned by Heinemann as comparable to Wallach.

Our point was more general than this, however. Here are two quite similar studies, both using side-by-side, center/surround displays, yet they lead to two very different pictures of the data. One picture consists of a graded series of diverging functions, indifferent to qualitative boundaries, with an emasculated ratio principle emerging only within an arbitrary range of quantitative values. The other picture presents a ratio principle (parallel functions) as fundamental, with qualitative boundaries (especially the increment-decrement threshold) as decisive, with a shift to different patterns of data beyond those boundaries.

We claim that we have resolved some of these contradictions in the following ways:

First, Hess and Pretori did not find that increments are associated with luminance matching, because their procedure (surround adjustment) prevented such a match, forcing their data to take a form consistent with their theory. Heinemann $(1955,1961)$ did not make this mistake, and, consequently, he generally obtained luminance matching when his matching display was an increment. He says in a footnote (Heinemann, 1955, p. 93) that the functions he obtained with surround adjustment "differ in no significant way from those obtained when $S$ makes matches by varying the luminance of the test field" (center). Nevertheless he must acknowledge that the functions he obtained, particularly the flat sections that represent luminance matching of infields, could not possibly have been obtained using surround adjustment. Interchangeability of surround adjustment and center adjustment ap- 
plies only where the ratio principle is found, that is, where things are relative, as one would expect.

Second, the ratio principle should not be expected to apply at the extremes, where the surround luminance is far higher than the center luminance. Here, changes in either the center or the surround have no effect on the appearance of the center. We stand by our claim that Hess and Pretori's curves in this region (for instance, curve 2, called curve $A$ in some plots) cannot possibly mean what they are presented to mean-namely, matching of centers. Perhaps it is more accurate to say that center matching is represented, in this region, not by a line, but by a solid area. We showed that even with one center 16 times as bright as the other, forced choice selection of the brighter center is not better than chance. Heinemann ignores this result.

We also showed (Experiment 5, series A) that when a fair test is made, using center adjustment, the data at these contrast levels are distributed haphazardly-not systematically at all.

Heinemann believes there is no reason to assume, as we have done, that Hess and Pretori's observers matched surrounds under these conditions. We don't claim that the observers were trying to match surrounds, only that they did in fact match them and that this accounts for the systematic data for conditions in which none should be expected. Inspection of the surround luminance values from Table 1 (curve 2) in Flock and Tenney's (1970) translation of Hess and Pretori shows that the surrounds were matched to within $2.5 \%$ in the high contrast region of the curve. However, the reason for this surround matching now seems much simpler than our paper had suggested. Hess and Pretori began each series with both surrounds set to the same luminance. As they changed the center of the matching field, the observer saw no change and thus tended to leave the matching surround at the same value. Heinemann got the same result at the low end of his 1955 curves $\mathrm{D}, \mathrm{E}$, and F. As the center luminance is increased, the observer, seeing no change, leaves the surround luminance essentially unchanged.

Heinemann closes his commentary by saying that "if they exist at all, these qualitative boundaries are irrelevant to brightness perception." Yet, in all of his graphs (Heinemann, 1955, 1961), one almost always finds that the pattern of data changes when qualitative boundaries are crossed, including his most widely cited curves (Heinemann, 1955, Figure 3) in which approximately horizontal lines, when the target is an increment, change to approximately vertical lines, when the target changes to a decrement.

\section{REFERENCES}

AREND, L. E., \& Goldstein, R. (1987). Simultaneous constancy, lightness, and brightness. Journal of the Optical Society of America, 4, 2281-2285.

BECK, J. (1972). Surface color perception. Ithaca, NY: Comell University Press.

Evans, R. M. (1974). The perception of color. New York: Wiley.

Flock, H. R. NoGUCHI, K. (1970). An experimental test of Jameson and Hurvich's theory of brightness contrast. Perception \& Psychophysics, 8, 129-136.

Fry, G. A., ALPERN, M. (1953). The effect of a peripheral glare source upon the apparent brightness of an object. Journal of the Optical Society of America, 43, 189-195.

Haimson, B. R. (1974). The response criterion, the stimulus configuration, and the relationship between brightness contrast and brightness constancy. Perception \& Psychophysics, 16, 347-354.

Heggelund, P. (1964). Variables of perceived color. Journal of the Optical Society of America, 54, 1467-1474.

HeinemanN, E. G. (1955). Simultaneous brightness induction as a function of inducing and test-field luminances. Journal of Experimental Psychology, 50, 89-96.

HeinemanN, E. G. (1961). The relation of apparent brightness to the threshold for differences in luminance. Jourmal of Experimental Psychology, 61, 389-399.

HeinemanN, E. G. (1989). Brightness contrast, brightness constancy, and the ratio principle. Perception \& Psychophysics, 45, 89-91.

HELSON, H. (1943). Some factors and implications of color constancy. Journal of the Optical Society of America, 33, 555-567.

Hess, C., \& Pretor, H. (1970). Quantitative investigation of the lawfulness of simultaneous brightness contrast (H. R. Flock \& J. H. Tenney, Trans.). Perceptual \& Motor Skills, 31, 947-969. (Original work published 1894)

JACOBSEN, A., \& GiLChrist, A. L. (1988a). The ratio principle holds over a million-to-one range of illumination. Perception \& Psychophysics, 43, 1-6.

JACOBSEN, A., \& Gilchrist, A. L. (1988b). Hess and Pretori revisited: Resolution of some old contradictions. Perception \& Psychophysics, 43, 7-14.

JAMESON, D., \& HuRviCH, L. M. (1961). The complexities of perceived brightness. Science, 133, 174-179.

KaTZ, D. (1935). The world of color (2nd ed.; R. B. Macleod \& C. W. Fox, Trans.). London: Kegan Paul, Trench, Trubner. (Original work published 1911)

LIE, I. (1969). Psychophysical invariants of achromatic colour vision: I. The multidimensionality of achromatic colour experience. Scandinavian Journal of Psychology, 10, 176-184.

NoGUCHI, K., \& MaSUdA, N. (1971). Brightness changes in a complex field with changing illumination: A re-examination of Jameson and Hurvich's study of brightness constancy. Japanese Psychological Research, 13, 60-69.

WALLACH, H. (1948). Brightness constancy and the nature of achromatic colors. Journal of Experimental Psychology, 38, 310-324.

Whitrle, P., \& Challands, P. D. C. (1969). The effect of background luminance on the brightness of flashes. Vision Research, 9, 1095-1110.

Wyszecki, G., \& STILEs, W. S. (1967). Color science. New York: Wiley.

(Manuscript received September 8, 1988; revision accepted for publication September 21, 1988.) 